\title{
EREBEA
}

\author{
Revista de Humanidades \\ y Ciencias Sociales \\ Núm. 8 (2018), pp. 135-154 \\ ISSN: 0214-0691
}

\section{EL ARTE DE VIVIR DE LOS ÚLTIMOS INDÍGENAS, PATRIMONIO INTANGIBLE DE LA SABIDURÍA ANCESTRAL}

\author{
Francisco Giner Abati \\ Universidad de Salamanca
}

RESUMEN

Analizamos la situación de los últimos indígenas que actualmente viven dispersos en los distintos continentes, a pesar de las presiones crecientes de las sociedades desarrolladas a fin de explotar sus territorios. Sus culturas ancestrales les han protegido tanto de las enfermedades crónicas, producidas por el "progreso", como de muchos trastornos mentales, gracias a valores de respeto por la naturaleza y fuertes lazos de solidaridad grupal. El ritmo de vida de estos aborígenes, ligado a la naturaleza, es comparado con el estilo de vida estresante de nuestras sociedades industrializadas y consumistas.

La cuestión es qué podemos recuperar de estos valores perdidos y por otra parte, cómo podemos ayudar a estos pueblos que anhelan el desarrollo para que lo alcancen sin perder esos valores que les protegido hasta el presente.

\section{Palabras Clave}

Últimos Indígenas; Aborígenes; Sociedades primeras; Adaptación; Valores grupales; Solidaridad grupal; Salud mental.

Fecha de recepción: 2 de nov. de 2018

Fecha de aceptación: 30 de nov. de 2018

\section{Abstract}

We analyze the situation of the last indigenous people who currently live scattered in different continents, despite the increasing pressures of developed societies to exploit their territories. Their ancestral cultures have protected them both from chronic diseases, caused by "progress", and from many mental disorders, thanks to values of respect for nature and strong bonds of group solidarity. The rhythm of life of these aborigines, linked to nature, is compared to the stressful lifestyle of our industrialized and consumerist societies.

The question is what can we recover from these lost values and, on the other hand, how can we help these people who yearn for development to achieve it without losing those values that have protected them until the present.

\section{KeYwords}

Last Indigenes; First Societies; Adaptation; Group Values; Group Solidarity; Mental Health. 
Mi interés por la diversidad humana surgió ya en mi nińez cuando cayó en mis manos un libro con ilustraciones de los grupos humanos de los cinco continentes. Quedé fascinado por la diversidad humana y me propuse conocer esas versiones tan diferentes del ser humano. Mi experiencia de muchos años de interacción con los últimos indígenas me ha enseñado a valorar aspectos aparentemente sencillos de la experiencia humana.

\section{¿QUiENES SON LOS ÚlTimos Indígenas?}

Los grupos humanos actuales que denominamos "Últimos Indígenas" comprenden unos 370 millones de aborígenes; una minoría pues son el 5\% aproximadamente de la población mundial. Se encuentran diseminados en más de 90 países y protegen aproximadamente el $80 \%$ de la biodiversidad de la tierra. En algunos casos las fronteras nacionales los han dividido, como a los Masai, a los Herero, o a los Inuit. Los Peul, también conocidos como Fulani y Bororo se encuentran en ocho países africanos, padeciendo penalidades al atravesar fronteras teniendo que pagar aranceles ilegales debido a la corrupción. Algunos grupos indígenas son numerosos, como los Masai, 1.300 .000 individuos entre Kenia y Tanzania. Otros, en cambio, como los Hadza (Tanzania), o los Tau't Batu de Palawan (Filipinas) no llegan a los 500, y desgraciadamente algunos desaparecieron para siempre, como los Tainos del Caribe, los Delaware (USA), o los Fueguinos de América del Sur (Argentina y Chile), entre otras muchas tribus extinguidas en el planeta.

En nuestro estudio de los pueblos aborígenes no debemos fijarnos sólo en lo exótico y arcaico, sino en su sabiduría ancestral, que se expresa en su resistencia y en su capacidad de adaptación a través de sus formas de vida tradicionales. Es notable la apacible convivencia que se manifiesta en sus grupos compactos, y en los que el individuo se siente protegido y realizado. Su existencia se realiza en una sincronía con la naturaleza armoniosa y estable. El indígena no piensa que la naturaleza le pertenece y que puede usar y abusar de ella sin límites. Mas bien siente que él mismo forma parte de la naturaleza y que debe respetar el medio que le rodea como vida que forma parte del universo. Como los Batak de Palawan en Filipinas, que entienden que toda la naturaleza está albergada por espíritus llamados "Diwata" y que el uso que hagamos de la naturaleza ha de limitarse a obtener el alimento y los recursos para la existencia, sin extralimitarse desperdiciando recursos que no necesitamos consumir. Así viven del bosque, obteniendo 
de él todo lo necesario para satisfacer sus necesidades sin destruirlo. Son muchos de estos pueblos un auténtico ejemplo de sabiduría de explotación ambiental respetuosa y sostenible.

\section{VALOR DE los Últimos IndíGENAS}

Muchos de estos grupos humanos han sido capaces de sobrevivir hasta la actualidad, mostrando una gran capacidad de adaptación. Han sobrevivido a enfermedades, desastres climáticos y sobre todo a la presión creciente de las sociedades industriales, que siguen despojándoles de sus territorios y arrinconándoles en lugares inhóspitos, como el desierto del Kalahari, el frío Ártico o en las selvas amazónicas, aún de difícil acceso.

Estos pueblos han mantenido su cultura, con arte, lengua, creencias, múltiples habilidades y sobre todo valores de solidaridad y respeto a la naturaleza, que los pueblos que se consideran desarrollados, no siempre han exhibido. Valores humanos que nuestros antepasados tenían y posiblemente hemos olvidado por las presiones del mal entendido "progreso".

En nuestras sociedades desarrolladas no sabemos, al ritmo de desajuste psicológico que generan, cuanto tiempo seremos capaces de sobrevivir.

\section{Proyecto de Documentación Cultural Comparada}

En 1989 me surgió la posibilidad de acompañar al Prof. Irenäus Eibl-Eibesfeldt, (Instituto Max-Planck), discípulo de Konrad Lorenz, quien había recibido el Premio Nobel de Medicina en 1974 por su contribución al nacimiento de una nueva disciplina científica: la Etología, a una expedición al Kaokoland de Namibia y posteriormente al Kalahari en Botsuana. El Prof. Eibl siguió el mandato de su maestro Konrad Lorenz investigando las raíces biológicas del comportamiento en el ser humano, lo que dio lugar a otra nueva disciplina: la Etología Humana. Para ello era preciso documentar el comportamiento humano en grupos de diferente estrategia ecológica-económica y en los cinco continentes. Eibl comenzó el proyecto, en el que continuó investigando hasta su muerte en 2018, para el que rodó miles de kilómetros de negativo de $\$ 16 \mathrm{~mm}$ en distintos grupos humanos y sacó conclusiones acerca de la universalidad de muchos patrones de comportamiento en la especie Homo sapiens, tales como el saludo con elevación de cejas, y otros muchos.

Decidí continuar el proyecto y a lo largo de los años he ido documentando culturas de África, Sudeste asiático, y Pacífico, estando actualmente investigando en América. Primero rodamos en cine con negativo de $16 \mathrm{~mm}$, después con S16mm y actualmente en video de alta definición.

El estudio de las sociedades de pequeña escala, que podemos denominar primeras, nos permite explorar nuestro pasado de miles y quizás millones de años de evolución, con valores y patrones de comportamiento, que hemos practicado hasta hace relativamente poco tiempo. Encontramos coincidencias que, aunque 
con formas distintas, vienen a expresar una misma motivación, especialmente en el ámbito de las creencias, emociones y comunicación.

Analizando la historia del ser humano como especie podemos entender como los cambios acaecidos nos han llevado hasta la situación actual. Podemos prever el itinerario de pueblos en desarrollo y prevenirles para que no cometan los errores que nosotros cometimos, como la pérdida de valores grupales y solidarios, la contaminación del entorno y la aniquilación de recursos naturales. Por otra parte, comparándonos con ellos, podemos caer en la cuenta de que hemos olvidado esos valores de respeto por la naturaleza, generosidad altruista en la participación en el grupo, sobre los que podemos reflexionar y en lo posible intentar recuperar.

Ante el riesgo de sucumbir en el reto de adaptarnos a las condiciones estresantes del estilo de vida de las sociedades desarrolladas, no estaría mal compararlo con el de estos pueblos que hasta hace poco llamábamos desconsideradamente primitivos y antes incluso salvajes.

En primer lugar, hemos estado viviendo en comunidades pequeñas, en las que todos los miembros del grupo se conocían y esta situación creaba un clima de seguridad y confianza. El grupo protege a cada individuo y éste trata de comportarse solidariamente con el grupo. Recuerdo varios casos de mujeres solas, que en el seno del grupo estaban protegidas y nunca les faltaba atención. Entre los Afar del norte de Etiopía, recuerdo una mujer ciega, que es alimentada y atendida por sus familiares y vecinos y que vive feliz sintiéndose acompañada. Esto contrasta con casos de personas que mueren solas en sus apartamentos, sin que nadie las eche de menos, y solo al cabo de meses los vecinos se percatan de su fallecimiento.

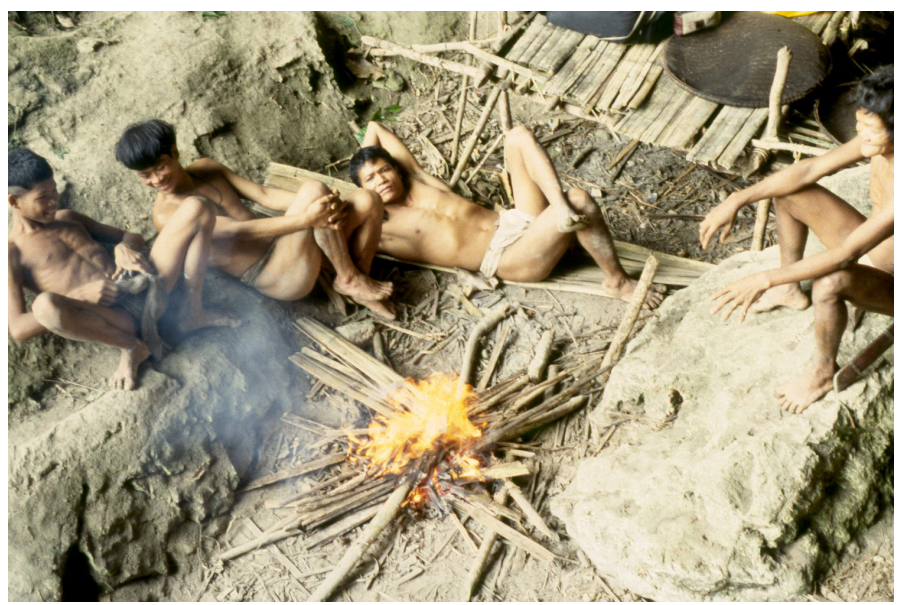

Foto 1. Tau't Batu-Palawan, Filipinas. 
RITMO DE VIDA CRONOBIOLÓGICO NATURAL

En las sociedades industrializadas el ritmo de vida estresante está causando estragos a un ritmo directamente proporcional con el grado de desarrollo alcanzado. Vivimos pendientes del calendario, con fechas límite y plazos que cumplir desde la escuela por exámenes y después en la vida laboral. Asimismo el reloj marca nuestras largas jornadas con horarios exigentes, transporte con horarios marcados y trabajos que a veces nos quitan horas de sueño, gracias a la luz eléctrica que nos permite alargar nuestras jornadas de trabajo. Todo ello conlleva un agobio al que es difícil sustraerse.

Este ritmo estresante contrasta con el estilo de vida de los pueblos primeros, cuya existencia está solo regida por los ritmos cronobiológicos naturales, el día y la noche.

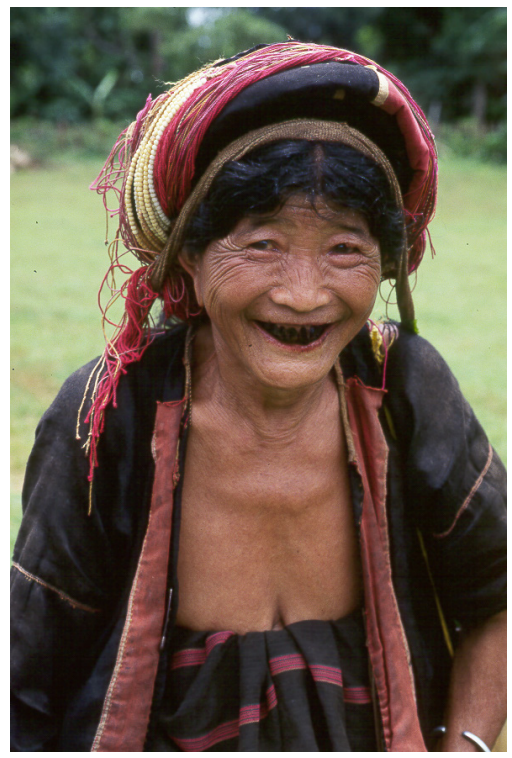

Foto 2. Pulong -Myanmar. Nunca encontré un paciente en estos grupos que se quejara de insomnio y la vida transcurre en general entre ellos de forma habitualmente tranquila y cuando han visto aceleración en mi actividad he recibido su crítica. Recuerdo una mañana cuando atravesaba con prisas el poblado himba de Mushila en el sur de Angola para preparar el equipo de filmación y aprovechar la primera luz de la mañana cuando Mushila, el jefe del poblado, me para y me recrimina por maleducado. Aquello me sorprendió. Que un pastor sin escolarización me llamara la atención por descortés. Mushila me explicó con detalle: "No puedes pasar por la mañana delante de las personas sin saludar siguiendo el protocolo". " ¿Wa penduka nawa? Que quería decir: “¿Has dormido bien?” Y seguía “¿todos bien?”... a lo que había que responder "todo bien", "nawa nawa". Me di cuenta de que aquello era mas sentido que el breve saludo con el que despachamos a los compańeros con los que nos cruzamos en los pasillos antes de entrar en clase.

Alimento natural obtenido y preparado CON El ESFUerzo propio, y SiN PROCESAR

A diferencia de nuestras sociedades consumistas que comemos alimentos refinados, y procesados con numerosos conservantes y potenciadores del sabor, los pueblos primeros obtienen su alimento directamente y lo consumen sin adulterar. Los mas sabios en este sentido son los cazadores -recolectores y los pescadores. Su dieta se ha comprobado es la más variada y sana, junto con un estilo de vida activo, en el que se anda mucho e incluso a veces se corre y en general requiere de una actividad física variada. Las mujeres Hadza, Baka o Ju/'hoansi recorren cada día, 


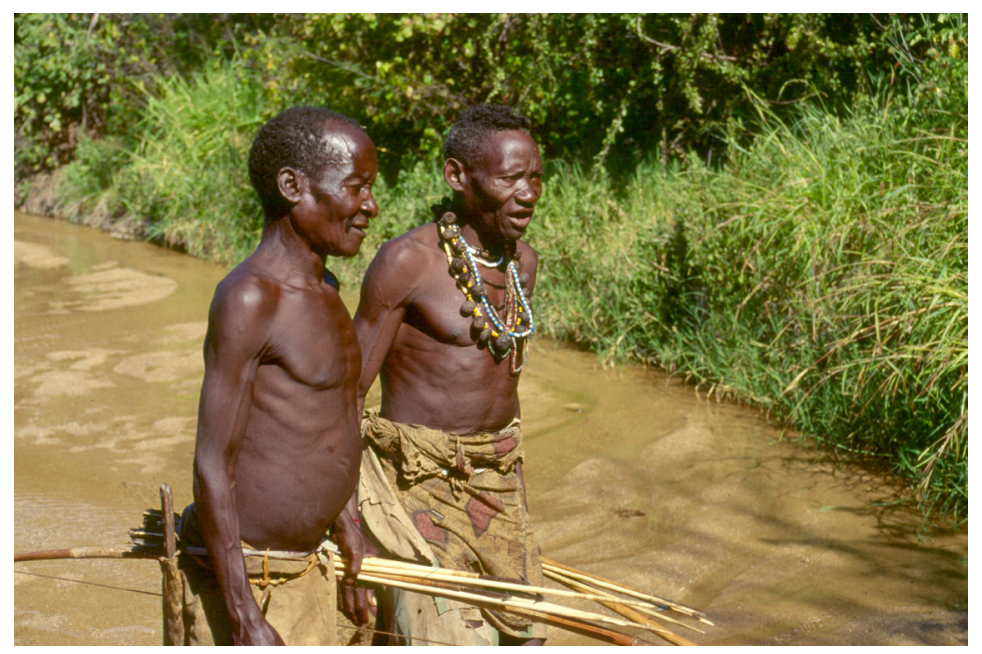

Foto 3. Cazadores Hadza.

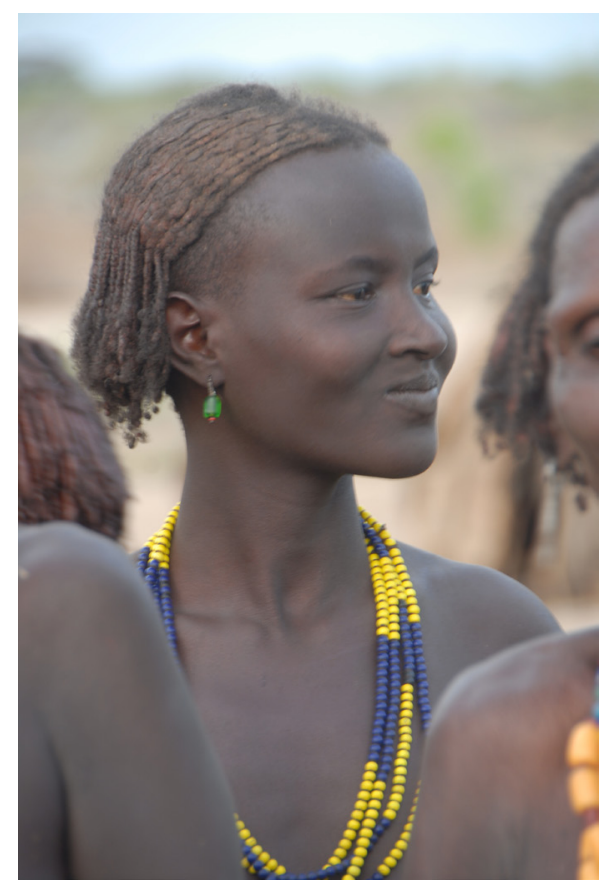

Foto 4. Jie-Sur Sudan. 
mientras van conversando, varios kilómetros mientras recogen alimentos silvestres: frutos, nueces, raíces, tubérculos y plantas comestibles, algunas medicinales. Esta actividad casi cotidiana les produce gran satisfacción, lo mismo que a los varones que salen a cazar en grupo, pasando a veces días y noches sin regresar a casa persiguiendo sus presas. Esta forma de vida considerada precaria, actualmente ha sido puesta en valor.

Así hoy hablamos en nutrición de la dieta del paleolítico, aludiendo a una forma de alimentación muy recomendable y que es muy parecida a la de estos cazadores que aún son capaces de vivir practicando la estrategia económico-ecológica mas antigua de la humanidad, en unos territorios cada vez más esquilmados por las sociedades complejas, que son poco respetuosas con los legítimos propietarios de los territorios que habitan. Cuando he acompańado a cazar a estos grupos, he llegado a comprender la emoción que sentían en sus expediciones y la satisfacción al llevar al hogar el alimento para sus familias. Este trabajo suponía esfuerzo, sacrificio y muchas privaciones.

La espontánea alegría de estos pueblos se expresa en la danza. No tienen propiedades, pero sienten una gran libertad que los anima a danzar en grupo casi cada noche a la luz de

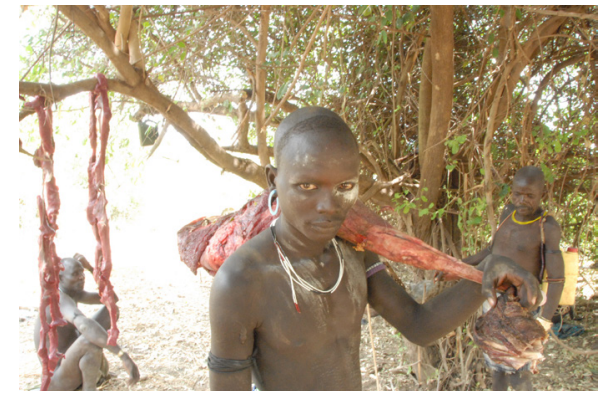

Foto 6. Cazadores Kweigu. Etiopía

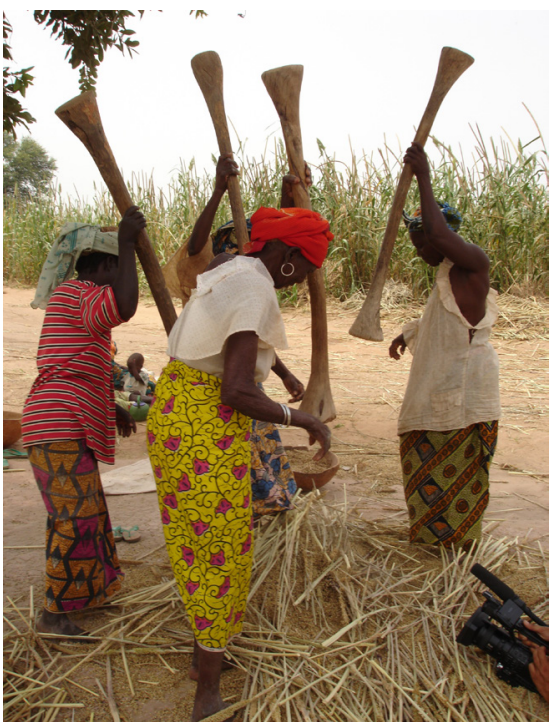

Foto 7. Agricultoras Dogon. Niger.

Foto 5. Baka Camerún. 
la luna. Recuerdo como los Baca en el Camerún disfrutaban al son del tambor ante la mirada de sus vecinos bantúes, cultivadores de cacao, quienes disfrutaban observando el enérgico ritmo de sus danzantes vecinos. Los Ju/'hoansi por su parte también celebraban el fin de una buena cena con su danza de trance, en la que canalizaban las energías del grupo para aliviar los dolores de algún miembro enfermo. La salud de los cazadores-recolectores es un ejemplo de adaptación. En mi experiencia como médico pude comprobar que tanto su salud mental como física es la mejor que he encontrado entre distintos grupos humanos.

Los pastores a su vez practican un estilo de existencia en el que los valores de la familia y el grupo armonizan sus vidas. Se alimentan básicamente de leche que suelen consumir directamente o en forma de cuajada. La carne de los animales solo es consumida en ocasiones rituales y festivas. Complementan su dieta con vegetales que obtienen de la recolección, o del intercambio con sus vecinos agricultores. Es el caso de los Peul, que proporcionan leche a los Hausa, a cambio de la que reciben cereales. Los Somalíes, pastores de camellos, toman el té con leche de camella, e incluso tienen que limpiar sus cacharros con las brasas del fuego dada la escasez de agua en su medio.

La salud de los pastores, aunque no tan buena como la de los cazadores, es aún notable. Dado que la leche es un alimento 100, que contiene todos los nutrientes necesarios, colabora a que los jóvenes crezcan sanos y fuertes, junto a una generosa actividad física con el ganado.

Los agricultores con su obligado sedentarismo practican un patrón de existencia mas rutinario, un trabajo físico mas monótono, y se suelen alimentar con dietas mas monótonas, a base de maíz, arroz, mijo o algún otro cereal. Las frutas y verduras alivian esta monotonía. Les afligen algunas enfermedades zoonóticas, tales como la tuberculosis o la fiebre de Malta, debido a su cercanía con el ganado.

\section{Ausencia de Frustraciones Biológicas}

La vida sexual, dentro del pudor habitual observado transculturalmente, transcurre generalmente en muchos de estos pueblos de una forma bastante relajada. Los jóvenes se inician en las relaciones sexuales en época temprana. En general la sexualidad y la reproducción no van separadas, dada que la vida es un bien que todos desean y valoran. Así, entre los Herero, no es un problema para una joven quedar embarazada, pues este hecho es considerado normal y deseable. No afectará a su posterior matrimonio, puesto que si hubiera hijos, estos pasarían a formar parte de la nueva familia y aceptados por el esposo como hijos. Los guerreros Masai reciben en sus campamentos la visita de sus amantes, aunque no siempre se convertirán en esposas.

Infancia Plena de Factor Social

Los niños necesitan para su correcto desarrollo mental una serie de interacciones psicológicas, sobre todo afectivas, amor y cariño, que serán tanto mas ricas 


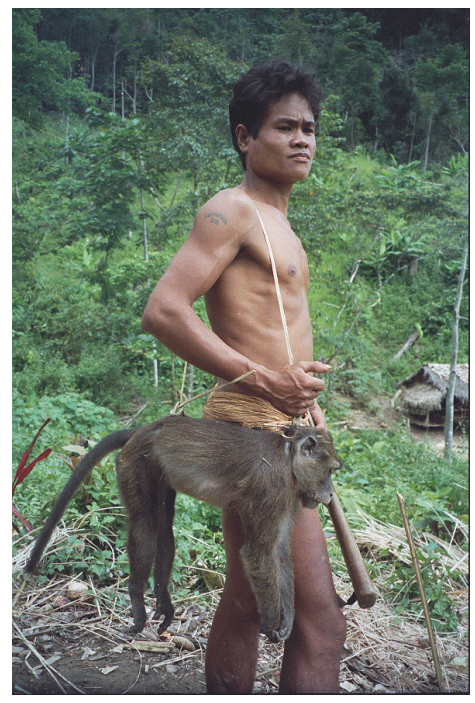

Foto 8. Batak. Filipinas.

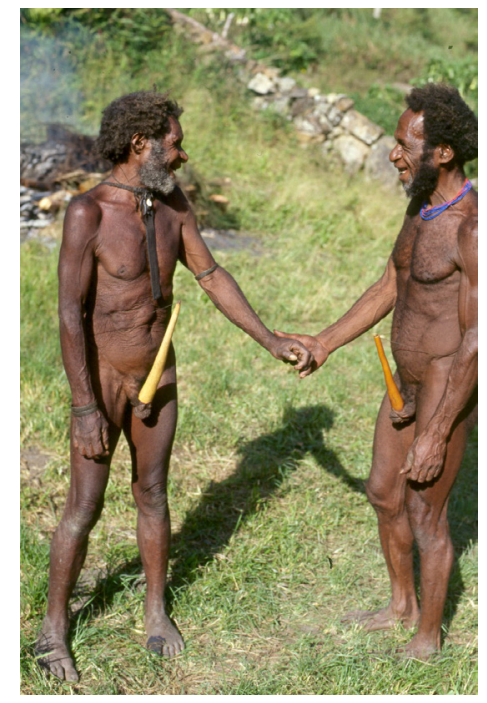

Foto 9. Dani-Irian Jaya.

cuantas mas personas haya en su entorno. Dado que en estos pueblos tradicionales predomina la familia extensa, los niños se encuentran protegidos y rodeados de otros nińos de distintas edades y de numerosos adultos. Recuerdo que entre los Hakahona, los niños, y continuando de adultos, llaman "mama", no solo a su madre biológica sino también a todas las hermanas de su madre y hermanos también a sus primos. Madre pequeña, si se trata de una hermana menor de su propia madre y madre mayor si es de más edad.

Muy importante para el desarrollo de los niños es el juego con sus iguales y las interacciones en general, para ensayar el comportamiento. Esto se posibilita en estas sociedades en las que el niño está rodeado de otros niños, a diferencia de nuestras familias en las que hay pocos hijos y que además viven bastante aisladas.

Los niños tienen mucho tiempo libre y colaboran pronto en las tareas que su edad les permite. Estas actividades, que consisten en por ejemplo ocuparse del ganado menor, o en recoger plantas, les proporciona un sentimiento de reconocimiento y valoración por parte del grupo. Los niños mayores suelen cuidar de los mas pequeńos y estos aprenden a ajustar sus comportamientos con el patrón de los mayores.

Me sorprendió que estos niños, que no habían recibido escolarización, eran sin embargo de adultos magníficos oradores en público y se sentían seguros, mostrando personalidades psicológicamente equilibradas y socialmente muy hábiles en la comunicación social. 


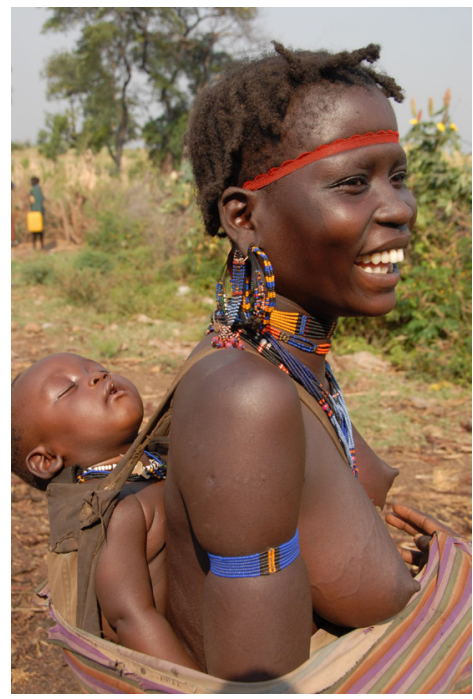

Foto 10. Jie. Sur Sudán.

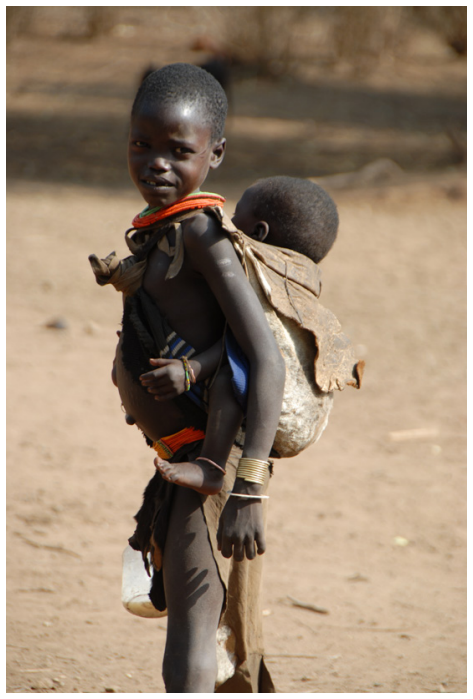

Foto 11. Jie. Sudan del Sur.

\section{INTEGRACIÓN DEL INDIVIDUO EN LA COMUNIDAD}

Los niños van creciendo en el seno de una comunidad en la que participan activamente desde muy jóvenes. Este sentimiento de pertenencia se va fortaleciendo cotidianamente gracias a esa riqueza de interacciones impregnadas de emociones,

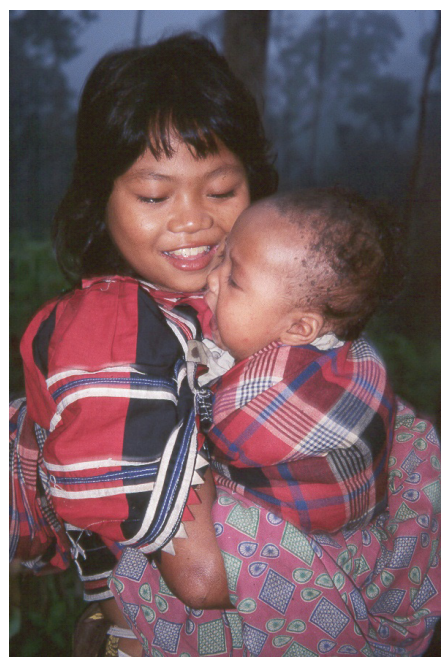

Foto 12. Matig Salug.

Mindanao, Filipinas. sobre todo de afecto y cariño. Niños y niñas participan activamente en las actividades del grupo, saliendo a pescar o a recoger frutos, buscando leña o yendo a por agua, cuidando de un hermano mas pequeño o ayudando a la abuela anciana. El estrés en la competencia vital es escaso, dado que todos alcanzarán un puesto en su grupo, y el grupo a su vez, a modo de seguridad social, proporciona a cada uno lo necesario en su existencia. Así se puede entender el caso del matrimonio concertado, en el que los padres procuran la mejor pareja a su alcance para sus hijos. Entre los Masai, por ejemplo, ningún individuo es desatendido por la familia y el grupo, desde el nacimiento hasta la muerte. Nadie pasa hambre $\mathrm{y}$ todos son protegidos y atendidos en su vejez. 


\section{Realización Fluida de las Tareas Sin Estrés}

Los cazadores y recolectores salen al bosque en busca del alimento de una forma casi deportiva y obtienen satisfacción en el proceso de su obtención. Recuerdo cuando pregunté a un cazador Baka por lo que consideraba mas importante en su vida, me contestó que sin duda era el bosque, y que no podía pasar mas de un par de días sin volver a él. Cuando le pregunté por su religión, concepto que hube de explicarle como pude, me respondió que la caza. Los Twa de Angola y Namibia, cuando no encuentran caza, se han adaptado a alimentarse de tortugas y gusanos y al final del día danzan animosos a pesar de sus dificultades.

Los pastores se desplazan con sus ganados en busca de pastos y su trashumancia les hace felices. Cuentan los Bororo que un pastor sabe donde nació, pero no dónde morirá. Solo la reciente escasez de lluvias les está afectando, pues no encuentran forma de evitar que sus ganados mueran de hambre.

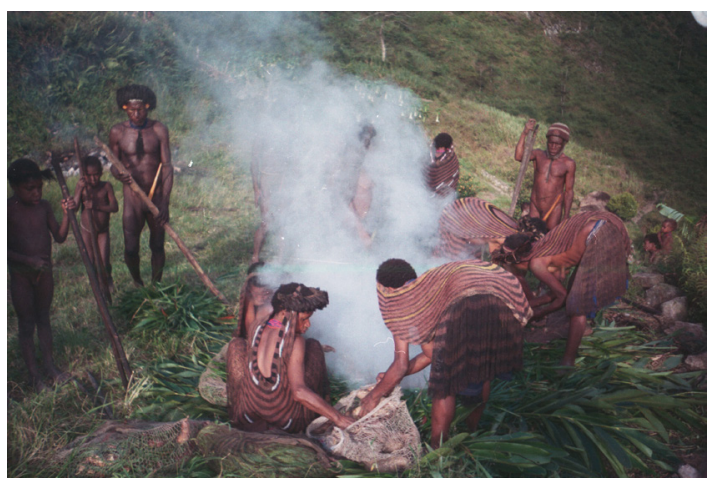

Foto 13. Dani. Irian Jaya.

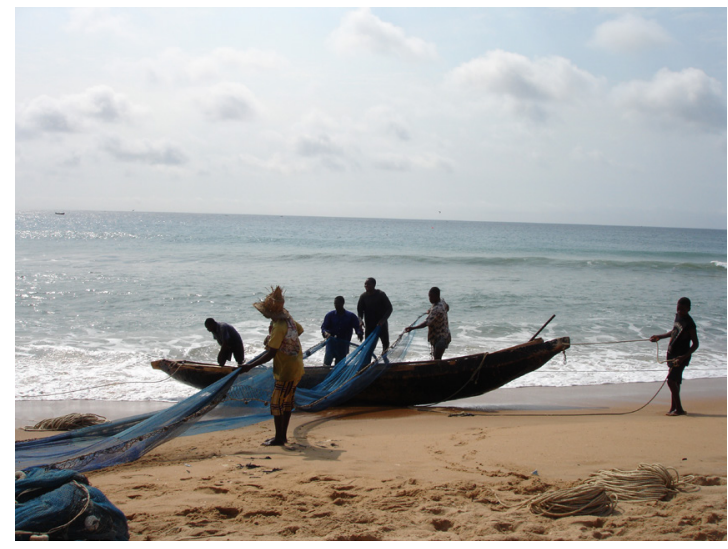

Foto 14. Pescadores Ewe. Ghana. 
Los agricultores trabajan duro en todo el proceso desde la limpieza y preparación del terreno hasta la siembre y recogida de la cosecha, pero no se marcan fechas límite en la terminación de un trabajo.

\section{Confrontación con Experiencias Existenciales}

En estos pueblos aun sin escuelas, electricidad, ni servicios de ningún tipo, solo su ingenio y capacidad adaptativa les ha permitido sobrevivir. El niño desde su nacimiento sólo dispone de las propias experiencias existenciales de las que se nutre y de las que aprende.

A diferencia de las sociedades con escritura, estos pueblos ágrafos han de ajustar su vida a partir del enriquecimiento que sólo la experiencia proporciona. Las tradiciones orales ayudan en esta tarea de aprender a vivir a partir de la experiencia. Mientras que en nuestras sociedades dedicamos a la teoría una parte considerable de nuestro tiempo, en estos pueblos los nińos, y después sigue el proceso en los adultos, ajustan su vida a partir de la impronta de la experiencia, que sólo se puede aprender con la experiencia. Es por ello que suelen manifestarse bastante sensatos y realistas en sus modos de vida tradicionales, estando poco dispuestos en ocasiones al cambio.

La pregunta es por qué unos pueblos se han transformado y evolucionado tanto hasta dar lugar a grandes civilizaciones, con sofisticada tecnología y otros se han quedado anclados en sus tradiciones sin apenas cambiar. Tal modo de vida, aunque sencillo, ha debido de haberles mantenido en un grado de satisfacción existencial, que ha hecho que prefieran la calma rutina de sus actividades que les proporcionan sustento, pero sobre dodo un grado suficiente de realización existencial, viviendo en grupos bien cohesionados, queriéndose, reproduciéndose y muriendo acompañados por sus descendientes.

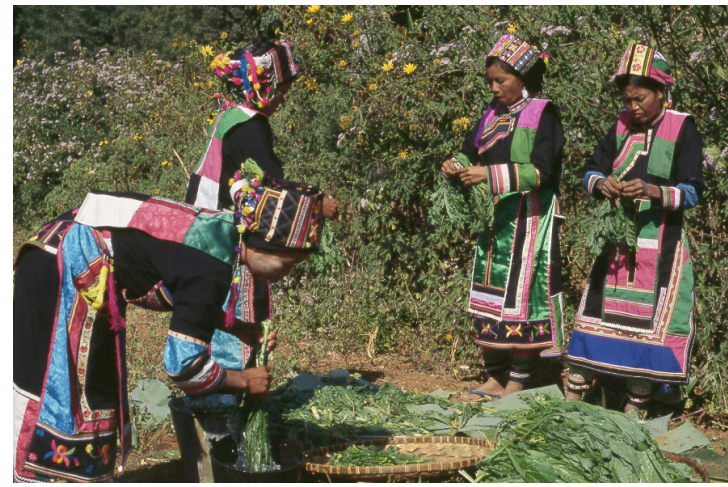

Foto 15. Lisu. Myanmar.

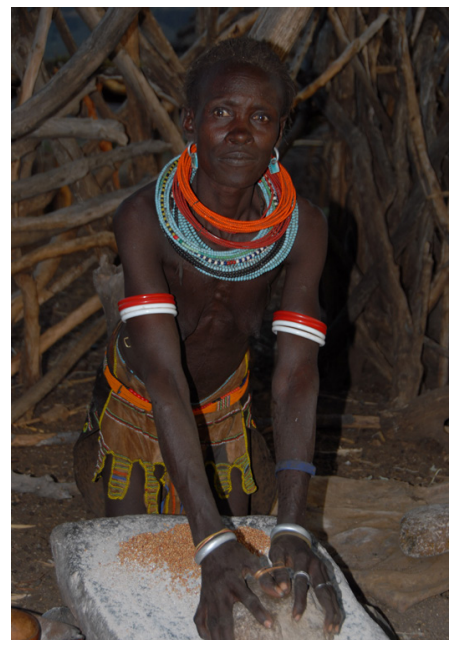

Foto 16. Topossa. Sur Sudán. 
Ceremonias que Regulan el Equilibrio y Bienestar del Individuo y de la Comunidad

Los grupos humanos que viven seguros en sus tradiciones encuentran en las ceremonias y rituales de sus culturas un auténtico termostato, que regula las emociones de los individuos y de la comunidad. Toda la existencia está marcada por la vivencia emocional de estas ceremonias, que los acompañan desde el nacimiento hasta la sepultura. Los ritos marcan y comunican socialmente el comienzo de cada etapa de la vida.

El nacimiento de un nuevo ser es celebrado con alegría, expresando el triunfo de la vida, cuyo único secreto es la misma vida. Y este es el mayor valor de estas comunidades, que aún siguen vivas a pesar de las dificultades que la civilización vecina les causa.

Los ritos de paso de la niñez a la vida adulta suelen estar bien marcados, para que todos sepan de la noticia de una nueva mujer o de un varón. Esto se celebra con gran alegría y participación de todos. Los pastores sacrifican animales para que el grupo se alegre y se fortalezca en esas marcadas celebraciones. Las bodas pueden, aunque no siempre, anunciarse con rituales que festejan comunicando a todos la unión de una pareja. Posiblemente el entierro y funerales sean las ceremonias más importantes que tratan de aliviar al grupo de la pérdida de seres queridos, que nos antecedieron en la vida y a los que debemos la existencia.

\section{Calidad de Vida}

En nuestra investigación intentamos conocer el grado de bienestar y calidad de vida de estos últimos indígenas, a través de una serie de preguntas que tratan

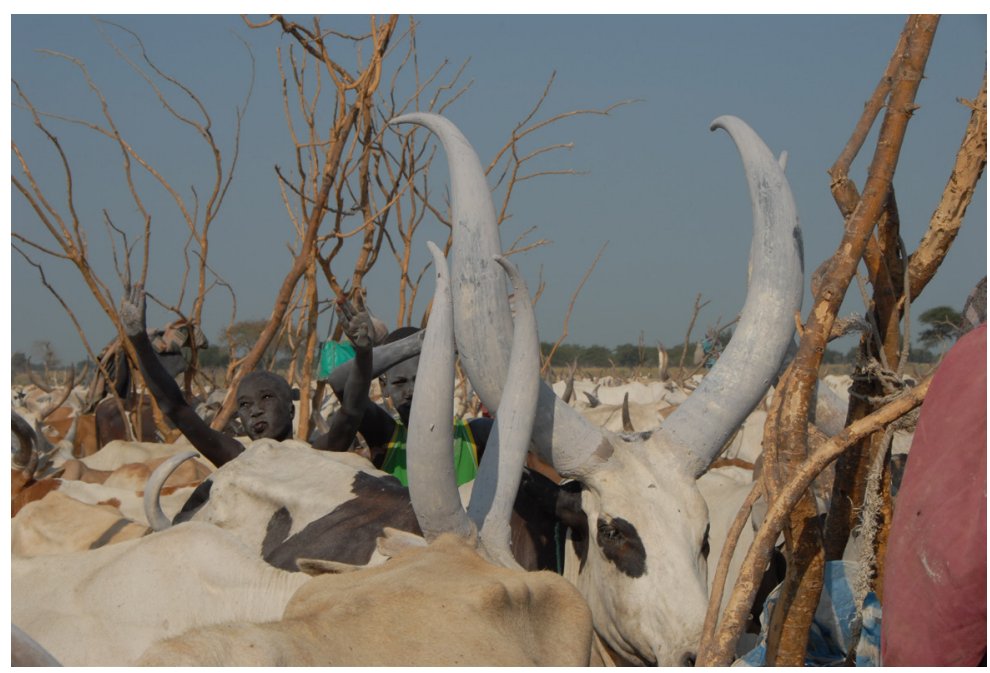

Foto 17. Nuer. Sur Sudán. 


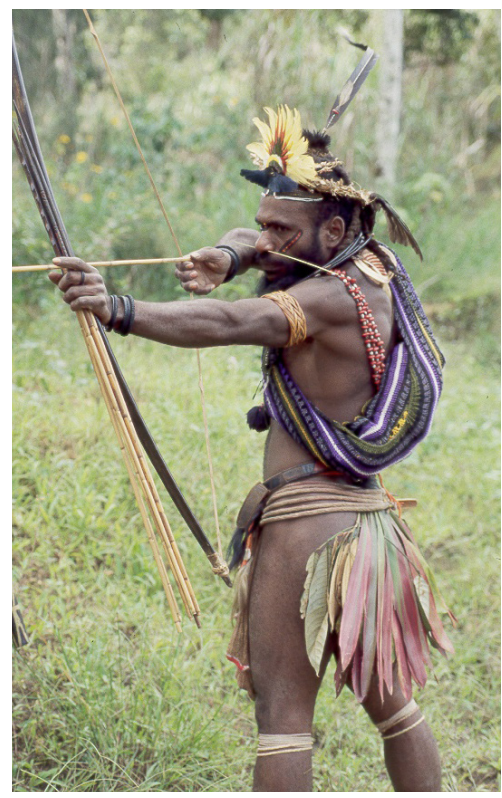

Foto 18. Papua Nueva Guinea.

de averiguar el grado de satisfacción de los que consideramos factores básicos para una vida, si no feliz, cercana al bienestar vital y a la realización personal de los individuos. Para ello investigamos los siguientes aspectos:

- Salud psicológica, física y social, prestando especial atención a la enfermedad metal.

- Calidad del medio ambiente en el que viven.

- Recursos que pueden obtener del entorno para alimentarse y dar respuesta a las necesidades básicas de vivienda, seguridad y protección.

- Sociedad en la que viven y calidad emocional de las interacciones sociales para llevar una existencia satisfactoria.

- Valores y creencias que proporcionan seguridad existencial y un sentido a la vida.

\section{SALUD}

En cuanto a la salud observamos que físicamente presentan en general una fortaleza notable y resistencia al esfuerzo físico con ausencia de obesidad y ningún caso de anorexia. Sufren enfermedades infecciosas, que logran vencer con la activación de su propia inmunidad y el uso de medicinas tradicionales basadas en hierbas medicinales. En cambio no sufren enfermedades crónicas, muchas de ellas causadas por el progreso, como colesterolemia, obesidad y el consiguiente infarto agudo de miocardio, diabetes y cáncer. 


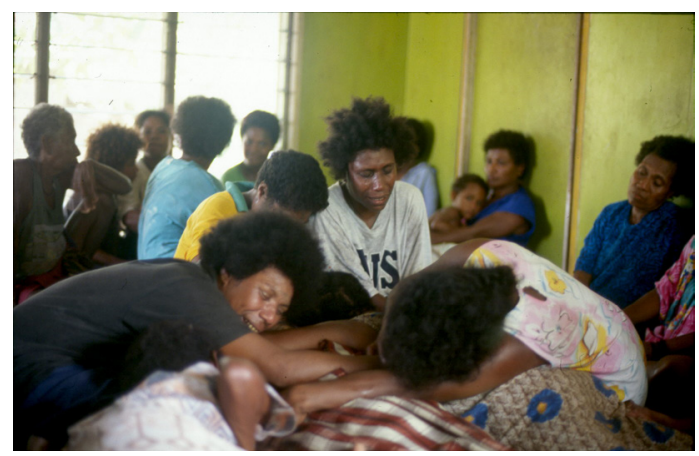

Foto 19. Funeral en República Centro África.

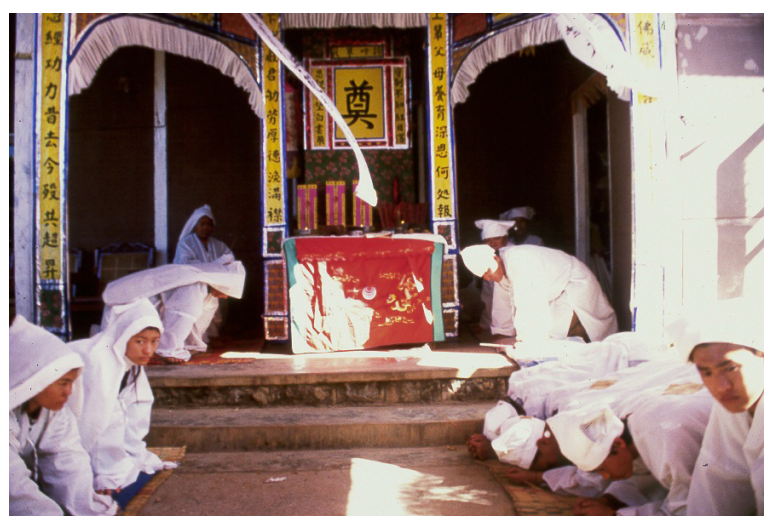

Foto 20. Funeral Kokang. Myanmar.

Desde el punto de vista psicológico no se observan trastornos mentales y no se quejan de dolencias que puedan reflejar trastornos frecuentes en nuestras sociedades desarrolladas, tales como depresión, ansiedad, insomnio, anorexia y tampoco se observan dependencias a tabaco, alcohol ni drogas. Como anécdota en muchas de las sociedades indígenas no conocen la categoría depresión, y no tienen un término para ella.

Desde el punto de vista de la salud social, su grado de integración en el grupo y su satisfacción vital en su participación es notable.

\section{Medio Ambiente}

En general, al vivir en lugares remotos con escasas comunicaciones, viven en ambientes limpios, sin contaminación aérea, lumínica, ni acústica. El agua, aunque a veces escasa, es potable y limpia. Entornos como el bosque tropical, en el caso de los Hadza, la selva en el de los pigmeos, el desierto con los Koisánidos, los Afar, los Saharauis, la sabana o el sahel en el de pastores como los Masai o los Herero son lugares aún sin contaminar. El problema cada vez más acuciante es 
que están siendo desplazados por la presión de los gobiernos, sobre todo cuando sus territorios son ricos en recursos como la caza o la madera.

\section{RECURSOS ECONÓMICOS}

Los indígenas han sobrevivido gracias a estrategias económico-ecológicas que se han mostrado eficaces y que les han permitido llegar hasta el presente. La caza ha sido un modo de vida que la humanidad ha practicado durante millones de años y que sólo actualmente está siendo cada vez mas difícil de mantener debido a la usurpación de los territorios ricos de caza o a la disminución del número de animales debida al empleo de armas de fuego, por parte de cazadores foráneos. Aún así los cazadores actuales se muestran satisfechos con su estilo de vida gratificante, a pesar de las dificultades.

Los pastores, por su parte, llevan una vida armoniosa, aunque sufren penurias en casos de sequías pertinaces, que a veces les hacen padecer durante ańos. Las fronteras impuestas por los gobiernos coloniales y la inseguridad también les hace sufrir. El robo de ganado es un mal que les hace tener que defenderse y organizarse como culturas guerreras. Es el caso de los Masai, Datoga, Turkana y otros muchos.

Los agricultores tienen mayor seguridad alimentaria, gracias a las reservas de sus graneros, por lo que solo se ven afectados por su tipo de alimentación monótona, que suele carecer de algunos elementos como proteínas o vitaminas. Las sociedades mixtas, que combinan la agricultura con algunos animales se alimentan mejor y junto al comercio satisfacen sus necesidades. A veces, las disputas con los pastores, cuyos animales irrumpen en sus campos, les cusan molestias mas o menos graves, teniendo que negociar o defender sus cosechas.

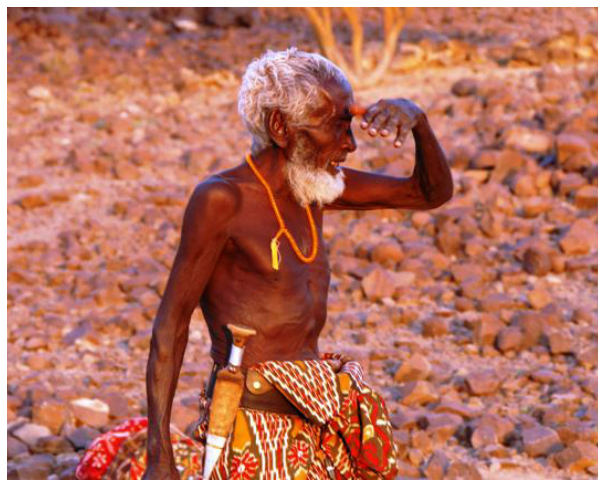

Foto 21. Anciano Afar.

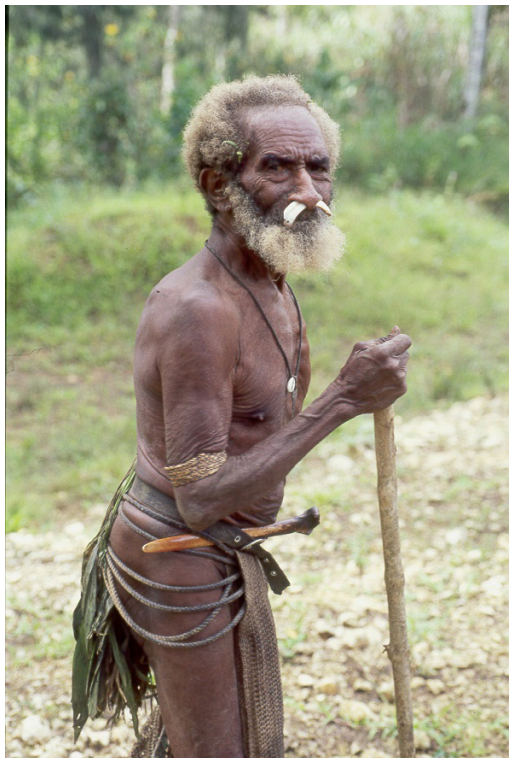

Foto 22. Papúa Nueva Guinea. 


\section{SOCIEDAD}

Los últimos indígenas viven en grupos familiares estables, en el seno de clanes que les protegen y en grupos étnicos, que se ayudan y realizan intercambios variados. El caso es que viven protegidos en dichos grupos por una especie de seguridad social, que hace que realicen sus vidas de una manera apacible y se reproduzcan. Parece que dentro del grupo encuentran vínculos emocionales que les proporcionan seguridad y una existencia con un grado de realización personal satisfactorio.

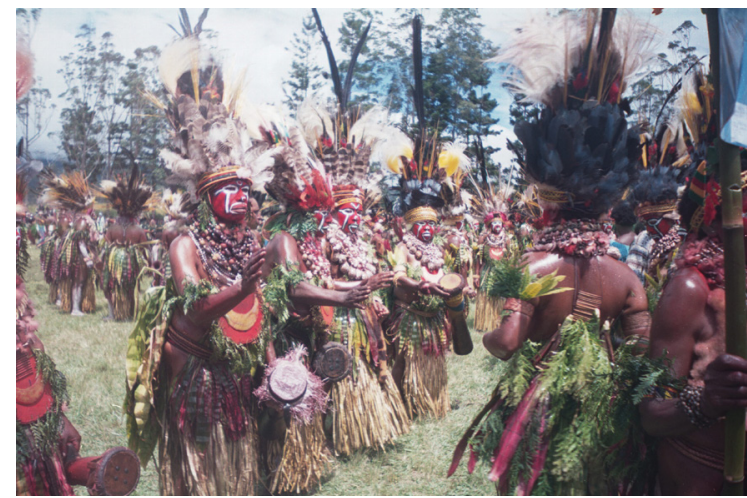

Foto 23. Tierras Altas. Papúa Nueva Guinea.

\section{Valores y Creencias}

Estos grupos tradicionales tienen un conjunto de creencias, con frecuencia asociadas a relatos míticos que les proporcionan una cosmovisión y con ello una seguridad en la existencia y un sentido a sus vidas. Valores clásicos, tales como el amor a la familia, la hospitalidad, el respeto a los mayores y la relación con la naturaleza contribuyen a mantener tradiciones sapienciales, que les orientan y les ayudan a llevar una existencia con un grado notable de realización personal y en una buena integración dentro del grupo. A pesar de ser sociedades ágrafas, sin códigos escritos y sin jueces ni policías, mantienen una conducta lógica y con profundo sentido ético de la justicia, que no dudan en mantener cuando alguien transgrede las normas implícitas en el conocimiento del grupo.

Encontrándome en Uganda celebrando una tarde la fiesta de la cosecha entre los Ik, entablé conversación con un hombre, que estaba sentado en lo alto de la montaña, mientras niños y adultos danzaban animosamente. Me sorprendió con sus reflexiones propias de un filósofo, cuando contemplando el horizonte serenamente me dijo: "Nosostros los Ik, somos pobres, pero aquí en nuestras montańas somos los reyes del Universo". Posiblemente a los Ik, como a otros muchos últimos indígenas les gustaría disfrutar de las comodidades de la tecnología, pero en 
ese proceso de cambio social, posiblemente hayan de pagar el alto precio que en nuestras sociedades desarrolladas estamos pagando, con consecuencias tan graves como el estrés, las enfermedades crónicas o del "progreso" y sobre todo la enfermedad mental y en muchos casos la soledad, a pesar de vivir rodeados de masas en las grandes ciudades.

Hoy casi no nos atrevemos a hablar de felicidad y solo nos referimos a grados de satisfacción o a calidad de vida. La pregunta es que nos ayuda a ser felices en la existencia y que nos lo impide.

En nuestra sociedad necesitamos hacer una reflexión acerca de nuestro estilo de vida, que aunque eficaz y productivo, como efectos secundarios y no deseados nos lleva a veces a la enfermedad, a la soledad y a la infelicidad. La sabiduría existencial de los últimos indígenas, en tanto que portadora de valores que les han ayudado a llegar hasta aquí, con dignidad, solidaridad y respeto a la naturaleza, merecen la consideración de formar parte del patrimonio inmaterial de la Humanidad.

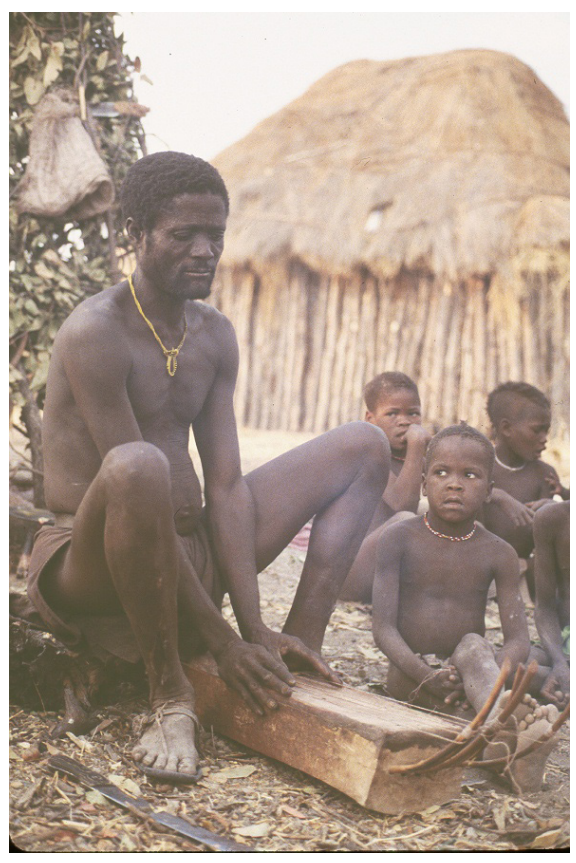

Foto 24. Vatwa. Angola.

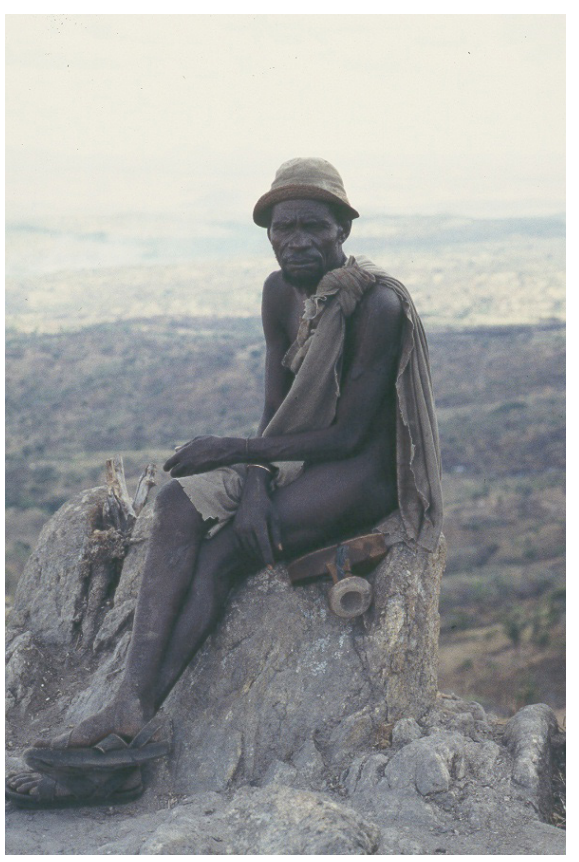

Foto 25. Ik. Uganda. 


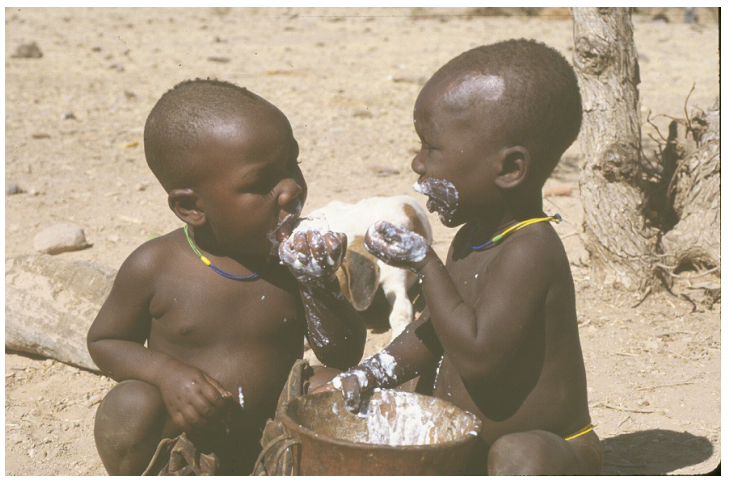

Foto 26. Zemba. Namibia.

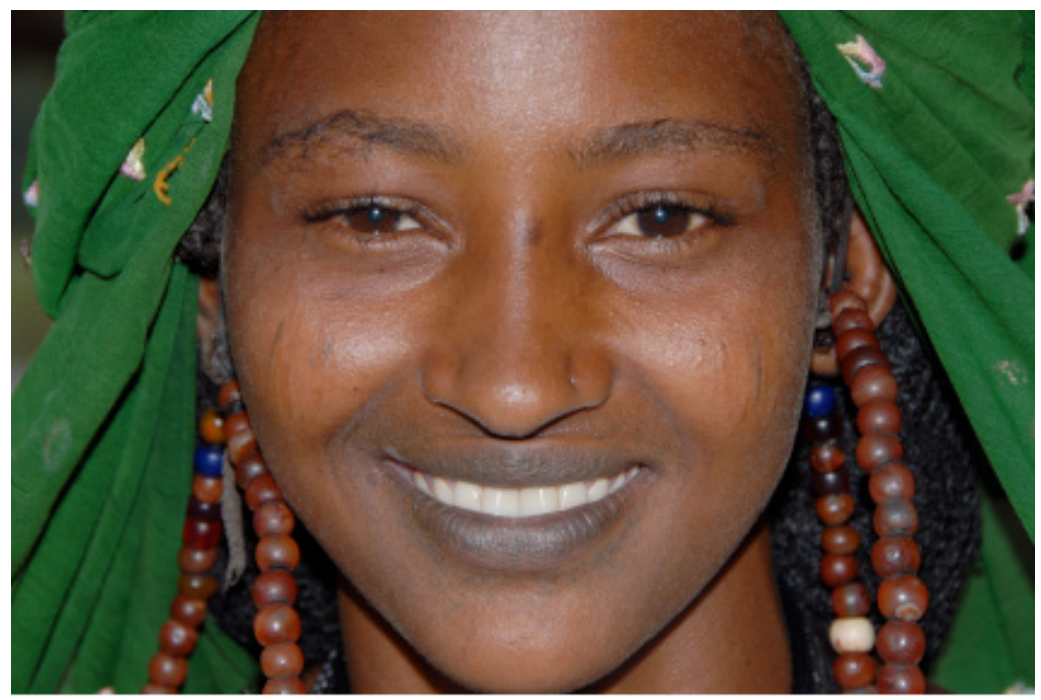

Foto 27. Muchacha Peul, Tchad. 